doi:10.1016/j.jviromet.2006.06.024

Copyright (c) 2006 Elsevier B.V. All rights reserved.

\title{
Diagnosis of Norovirus outbreaks by commercial ELISA or RT-PCR
}

\author{
Erwin de Bruin *, Erwin Duizer, Harry Vennema and Marion P.G. \\ Koopmans
}

Corresponding author. Tel.: +3130274 3738; fax: +3130274 4418 .

Diagnostic Laboratory for Infectious Diseases and Perinatal Screening, National Institute for Public Health and the Environment (RIVM), P.O. Box 1, 3720 BA Bilthoven, The Netherlands

Received 2 March 2006; revised 14 June 2006; accepted 22 June 2006. Available online 9 August 2006.

\begin{abstract}
The IDEIA Norwalk-like virus (Dakocytomation Ltd., Ely, United Kingdom) and the Ridascreen Norwalk-like virus enzyme immunoassay (R-Biopharm AG, Darmstadt, Germany), were evaluated for the diagnosis of outbreaks of acute gastroenteritis.

A panel of 158 fecal samples from 23 outbreaks, including confirmed rotavirus and astrovirus outbreaks, was used to determine the sensitivity and specificity of both ELISA kits relative to an RT-PCR protocol that was followed by Southern blot hybridization. Another panel consisted of 6 different genogroup I strains, 12 genogroup II strains and 1 genogroup IV strain and was used to determine the scope of the tests.
\end{abstract}

Compared to the RT-PCR, sensitivities of $38 \%$ and $36 \%$ and specificities of $96 \%$ and $88 \%$ were found for the Dako kit and the Ridascreen kit, respectively. Two genogroup I strains, and one genogroup II strain were not detected by the Dako kit, while five genogroup I and five genogroup II strains were not detected by the Ridascreen kit.

The sensitivity of both ELISA kits, and the scope of the Ridascreen are considered disappointing. However, the ELISA kits can be useful for a preliminary screening, provided that ELISA negative outbreaks will be re-tested by RT-PCR methods.

\section{Introduction}

Viral agents are the leading cause of gastroenteritis, with Norovirus (NoV) as the most common pathogen in almost all age groups (de Wit et al., 2001). NoV is associated commonly with large outbreaks in hospitals, homes for the elderly and other institutional settings, especially in the winter months. Transmission of NoV occurs by the fecal-oral route and is transmitted mostly person to person but may also be associated with contaminated food or water (Green et al., 2001). 
NoVs are a group of genetically diverse RNA viruses in the family Caliciviridae. Currently, based on the diversity of the capsid sequences, NoVs are grouped into five genogroups, of which three have been found in humans; genogroups I, II and IV (Koopmans et al., 2003).

Characterization of NoV has been hindered by the lack of a cell culture system or a small animal model (Duizer et al., 2004 and Rockx et al., 2005). For many years NoV has been diagnosed using electron microscopy (EM), reverse transcription polymerase chain reaction (RT-PCR), and "in-house" enzyme-linked immunosorbent assays (ELISA) (Atmar and Estes, 2001 and Rabenau et al., 2003). EM is a relatively insensitive method with a detection limit of approximately $10^{6} \mathrm{NoV}$ particles per gram of feces and it requires skilled personnel and sophisticated equipment (Atmar and Estes, 2001). ELISAs are generally easy to perform without the need for sophisticated equipment. However, due to the lack of sufficient quantities and quality of NoV antigens the availability of ELISAs for NoV detection has been restricted to in-house assays rather than assays that are available commercially (Vipond et al., 2000). Currently, the detection method used most widely is RT-PCR, however, several investigations are developing modification of this molecular detection method and methods such as real-time-RT-PCR, or multiplex-real-time RT-PCR protocols have been published (Richards et al., 2004 and Mohamed et al., 2006). These methods can be highly sensitive and specific, but detection of viral agents with molecular techniques also requires operator skills and sophisticated equipment. The use of highly purified antigens produced by molecular cloning techniques has resulted in the availability of commercial kits, and consequently more frequent use of ELISA techniques for the detection of NoV (Burton-MacLeod et al., 2004, Dimitriadis and Marshall, 2005, Richards et al., 2003 and Rabenau et al., 2003).

To the best of our knowledge this is the first report evaluating these two commercial ELISA tests with identical sample sets. The IDEIA NLV kit (DakoCytomation Ltd., Ely, UK) and the Ridascreen Norwalk-like virus EIA (Rbiopharm AG, Darmstadt, Germany) and an RT-PCR method which is used extensively (Vennema et al., 2002) were used to test fresh and stored stool samples for the presence of NoV. The sensitivity and specificity of both ELISA kits were determined, using a common RT-PCR assay as the "gold standard".

\section{Materials and methods}

\subsection{Fecal samples}

In this study, two panels of clinical samples were used. The first panel of 158 fecal samples from 23 different outbreaks was used to measure the sensitivity and specificity of both ELISAs for diagnosis of a gastroenteritis outbreak (Table 1 ). The samples were from outbreaks of gastroenteritis that had been tested for NoV by RT-PCR in 2002 and 2003; this panel included specimens from one outbreak that were found positive for Rotavirus and Astrovirus, two outbreaks that were found positive for Rotavirus only, and one that was positive for Astrovirus only. Stool samples were stored as $10-20 \%$ suspensions in Medium 199 with Hanks' salts and $25 \mathrm{mg} / \mathrm{l}$ gentamycine. All stool samples were tested directly or stored at $4{ }^{\circ} \mathrm{C}$ with a maximum of 2 months for the Dako kit. The samples were stored at $4^{\circ} \mathrm{C}$ and tested within 2 years by the Ridascreen kit. 
Journal of Virological Methods Volume 137, Issue 2 , November 2006, Pages 259-264

Table 1.

Detection of human NoV in stool samples with in-house RT-PCR and two commercial ELISA kits

\begin{tabular}{|c|c|c|c|c|c|c|c|c|}
\hline \multirow[t]{2}{*}{ Year } & \multirow[t]{2}{*}{ Outbreak number } & \multirow[t]{2}{*}{ Sequence type ${ }^{a}$} & \multirow[t]{2}{*}{ No. of samples } & \multicolumn{5}{|c|}{ No. of samples tested positive (\%) } \\
\hline & & & & PCR & Dako GGI & Dako GGII & Dako both & Ridascreen \\
\hline \multirow[t]{7}{*}{2002} & 173 & GGII.4 & 16 & $10(63)$ & $0(0)$ & $1(6)$ & $1(6)$ & $10(63)$ \\
\hline & 203 & GGII.4 & 8 & $6(75)$ & $0(0)$ & $0(0)$ & $0(0)$ & $0(0)$ \\
\hline & 206 & GGII.4 & 15 & $5(33)$ & $0(0)$ & $3(20)$ & $3(20)$ & $2(13)$ \\
\hline & 215 & GGII.4 & 7 & $7(100)$ & $0(0)$ & $7(100)$ & $7(100)$ & $3(43)$ \\
\hline & 222 & GGII.4 & 14 & $8(57)$ & $0(0)$ & $2(14)$ & $2(14)$ & $2(14)$ \\
\hline & 227 & GGII.4 & 6 & $5(83)$ & $0(0)$ & $0(0)$ & $0(0)$ & $1(16)$ \\
\hline & 229 & GGII.4 & 4 & $3(75)$ & $1(25)$ & $2(50)$ & $3(75)$ & $1(25)$ \\
\hline \multirow[t]{7}{*}{2003} & 13 & Rotavirus & 5 & $0(0)$ & $0(0)$ & $0(0)$ & $0(0)$ & $1(20)$ \\
\hline & 28 & Astrovirus & 5 & $0(0)$ & $0(0)$ & $0(0)$ & $0(0)$ & $0(0)$ \\
\hline & 37 & Rota- and Astrovirus & 7 & $0(0)$ & $0(0)$ & $0(0)$ & $0(0)$ & $0(0)$ \\
\hline & 48 & Rotavirus & 4 & $0(0)$ & $0(0)$ & $0(0)$ & $0(0)$ & $0(0)$ \\
\hline & 53 & GGII.4 & 6 & $6(100)$ & $0(0)$ & $4(67)$ & $4(67)$ & $6(100)$ \\
\hline & 54 & GGII.7 & 9 & $4(44)$ & $0(0)$ & $2(22)$ & $2(22)$ & $2(22)$ \\
\hline & 55 & GGI.6 & 4 & $2(50)$ & $0(0)$ & $0(0)$ & $0(0)$ & $2(50)$ \\
\hline
\end{tabular}




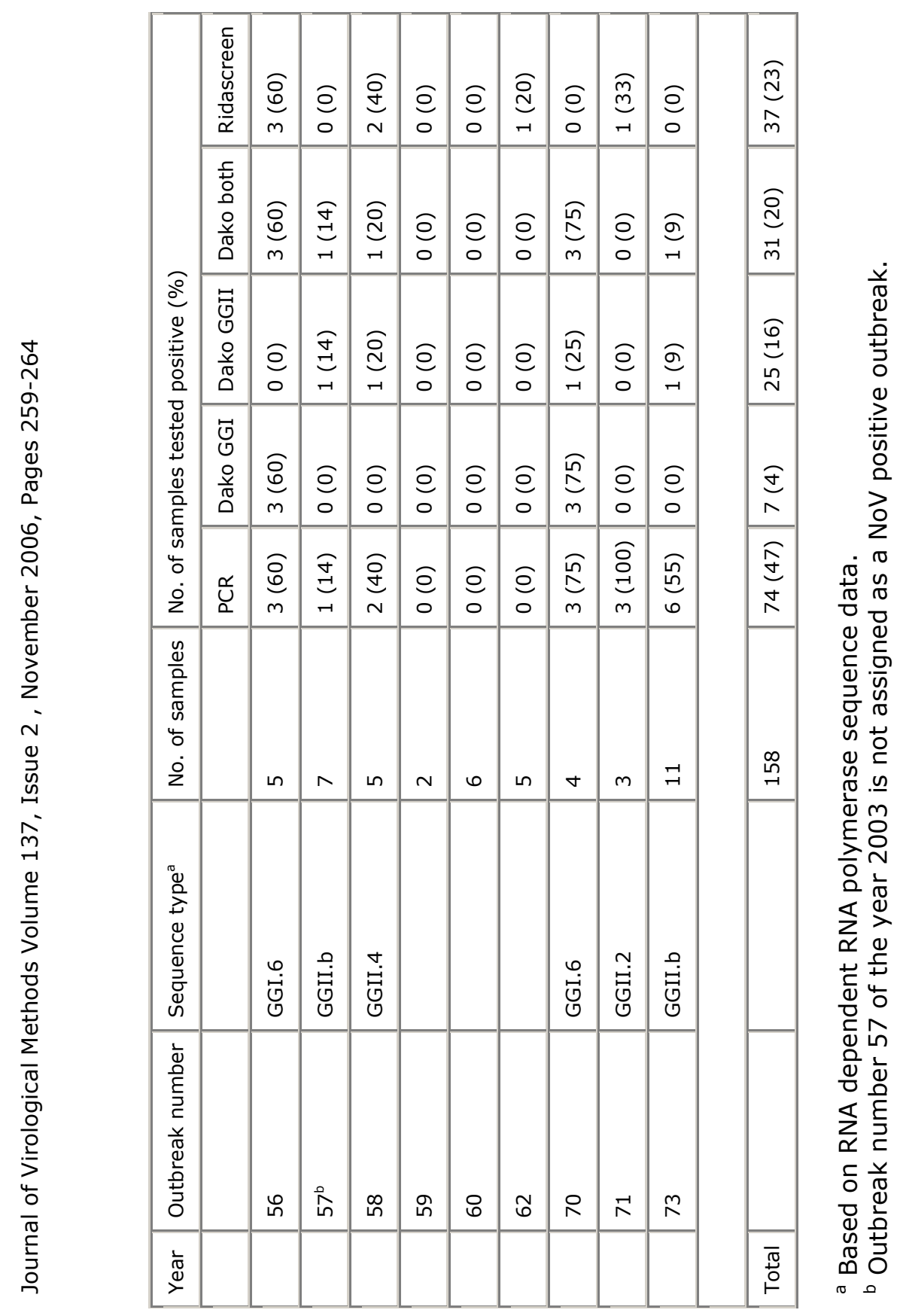


The second panel was composed to represent a wide variety of NoV lineages to evaluate the scope of the diagnostic tests. It consisted of 19 samples that were found positive for NoV by RT-PCR. The NoV lineages were typed by partial sequencing of ORF 2 . These stool specimens were collected from the Dutch gastroenteritis surveillance from 1999 to 2002. This panel contained 6 samples representing five genogroup I genotypes, 12 samples representing six genogroup II genotypes, and one genogroup IV strain (Table 2). Stool samples were stored as $10-20 \%$ suspensions in Medium 199 with Hanks' salts and 25 mg/l gentamycine at $-80^{\circ} \mathrm{C}$ until use.

Table 2.

Test results of the panel of NoV positive samples confirmed by RT-PCR, used to evaluate the breadth of the ELISA kits

\begin{tabular}{|c|c|c|c|c|c|}
\hline Strain & Genotype $^{a}$ & PCR & Dako GGI & Dako GGII & Ridascreen \\
\hline Hu/NV/IJsselstein57/2001/NL & GGI.2 & + & + & - & + \\
\hline Hu/NV/Driebergen45/2001/NL & GGI.3 & + & + & - & - \\
\hline $\mathrm{Hu} / \mathrm{NV} /$ NieuwLekkerland36/2000/NL & GGI.3 & + & - & - & - \\
\hline Hu/NV/Koudekerke38/2000/NL & GGI.4 & + & + & - & - \\
\hline $\mathrm{Hu} / \mathrm{NV} /$ Veendam05/2002/NL & GGI.5 & + & - & - & - \\
\hline Hu/NV/DenHaag45/2000/NL & GGI.7 & + & + & - & - \\
\hline Hu/NV/DenHaag08/2001/NL & GGII.1 & + & + & + & - \\
\hline Hu/NV/DenHaag09/2001/NL & GGII.1 & + & + & - & - \\
\hline Hu/NV/Rotterdam29/2001/NL & GGII.1 & + & - & + & + \\
\hline $\mathrm{Hu} / \mathrm{NV} / \mathrm{Delft} 48 \mathrm{M} / 2000 / \mathrm{NL}$ & GGII. 2 & + & + & - & + \\
\hline Hu/NV/Haarlem54/2001/NL & GGII. 2 & + & + & - & + \\
\hline $\mathrm{Hu} / \mathrm{NV} / \mathrm{Delft} 48 \mathrm{R} / 2000 / \mathrm{NL}$ & GGII. 3 & + & - & + & - \\
\hline $\mathrm{Hu} / \mathrm{NV} /$ Amsterdam14/1999/NL & GGII.3 & + & + & + & - \\
\hline Hu/NV/Coslada16/1999/SP & GGII.3 & + & - & + & - \\
\hline Hu/NV/Houten35/2001/NL & GGII.4 & + & - & + & + \\
\hline $\mathrm{Hu} / \mathrm{NV} /$ Zeeland26/2000/NL & GGII.4 & + & + & + & + \\
\hline $\mathrm{Hu} / \mathrm{NV} /$ Explosie13/2001/NL & GGII.4 & + & - & - & + \\
\hline Hu/NV/DenHaag47/2000/NL & GGII.5 & + & - & + & + \\
\hline $\mathrm{Hu} / \mathrm{NV} /$ Veghel12/2000/NL & GGIV $^{b}$ & + & + & - & - \\
\hline
\end{tabular}

a The genetic clusters shown are based on criteria described by Green et al. (2001). Where the roman character represents the genogroup and the second number represents the genetic cluster.

${ }^{\mathrm{b}}$ Genogroup IV is a prospective genogroup for the Alphatron/1998/NL-cluster. 


\subsection{RNA extraction}

RNA was extracted from $100 \mu \mathrm{l}$ of a $10-20 \%$ stool suspension by binding to sizefractionated silica particles in the presence of guanidinium isothiocyanate (GuSCN) and Triton-X100 (Boom et al., 1990). After centrifugation (1 min. at $13,000 \times g)$, the pellet was washed twice with a $500 \mu$ l GuSCN containing washing buffer, twice with $500 \mu \mathrm{l}$ ethanol $70 \%(\mathrm{v} / \mathrm{v})$, and once with $500 \mu \mathrm{l}$ acetone. After removal of acetone by evaporation, the RNA was eluted in $25 \mu \mathrm{l}$ distilled, DNAse RNase free water with $0.1 \mathrm{mM}$ DTT and RNAguard (250 units $/ \mathrm{ml}$ ) (Promega, Leiden, The Netherlands). The extracted RNA was either used directly in RT-PCR or stored at $-70^{\circ} \mathrm{C}$.

\subsection{RT-PCR protocol}

The RT-PCR was carried out as described previously (Vennema et al., 2002). Clinical samples were screened routinely with the primers targeting the RNA polymerase region. The RT-PCR for the capsid region is not tested routinely. Reverse transcription of $2.5 \mu \mathrm{l}$ of the extracted RNA was done for $60 \mathrm{~min}$ at $42{ }^{\circ} \mathrm{C}$ after annealing with RT-primer (Table 3). Reaction was performed in a $15 \mu \mathrm{l}$ reaction containing $0.3 \mu \mathrm{M}$ primer JV13I, $10 \mathrm{mM}$ Tris- $\mathrm{HCl} \mathrm{pH} \mathrm{8.3,50} \mathrm{mM} \mathrm{KCl,}$ $3 \mathrm{mM} \mathrm{MgCl}, 1 \mathrm{mM}$ dNTP and $5 \mathrm{U}$ AMV-RT (Promega, Leiden, The Netherlands). Five microliters of the RT-mix was added to $45 \mu \mathrm{l}$ of a PCR-mix containing $10 \mathrm{mM}$ Tris- $\mathrm{HCl} \mathrm{pH} \mathrm{9.2,50} \mathrm{mM} \mathrm{KCl,} 1.2 \mathrm{mM} \mathrm{MgCl}_{2}$ (final concentration $1.5 \mathrm{mM}$ ), $0.2 \mathrm{mM}$ dNTPs, 2.5 units ampliTaq and $0.3 \mu \mathrm{M}$ of PCR-primer (Table 3). Samples were denatured for $3 \mathrm{~min}$ at $94^{\circ} \mathrm{C}$ and subjected to 40 cycles at $94^{\circ} \mathrm{C}$ for $1 \mathrm{~min}, 37^{\circ} \mathrm{C}$ for $1 \mathrm{~min} 30 \mathrm{~s}$, and $72{ }^{\circ} \mathrm{C}$ for $1 \mathrm{~min}$. The low annealing temperature is vital to allow binding to a wide range of viral sequences. The amplification products were analyzed by $2 \%$ agarose gel electrophoresis and visualized with UV after ethidium bromide staining. 
Table 3.

Primers used for detection of NoV in stool specimen

\begin{tabular}{|c|c|c|c|}
\hline Function of primer & Primer name & Sequence $\left(5^{\prime}\right.$ to $\left.3^{\prime}\right)$ & Target \\
\hline \multirow[t]{3}{*}{ RT-primers } & JV13I & TCA TCA TCA CCA TAG AAI GAG & ORF 1 \\
\hline & $\mathrm{JV} 21$ & CCN RCM YAA CCA TTR TAC AT & ORF 2 (GGII) \\
\hline & $\mathrm{JV} 23$ & ATA TTI CCM ACC CAR CCA TT & ORF 2 (GGI) \\
\hline \multirow[t]{3}{*}{ PCR-primers } & JV12Y & ATA CCA CTA TGA TGC AGA YTA & ORF 1 \\
\hline & $\mathrm{JV} 22$ & GTA AAT GAT GAT GGC GTC TA & ORF 2 (GGI) \\
\hline & $\mathrm{JV} 24$ & GTG AAT GAA GAT GGC GTC GA & ORF 2 (GGII) \\
\hline Sequence primer & JV12S & ATA CCA CTA TGA TGC AGA & ORF 1 \\
\hline \multirow[t]{4}{*}{ Probes } & UK3 & GTC CCC TGA CAT CAT ACA GGC T & ORF 1 \\
\hline & JV5 & CTC ACC AGA GGT TGT CCA AGC & ORF 1 \\
\hline & GGI & ATG GAY GTT GGS GAY TAY RT & ORF 1 \\
\hline & GGII & GAA YTC CAT CRC CCA YTG & ORF 1 \\
\hline
\end{tabular}

\subsection{Southern blot hybridisation}

Confirmation of RT-PCR positive result was done by Southern blot hybridization. The RT-PCR products in the agarose gel were denatured by incubating in $0.5 \mathrm{M}$ $\mathrm{NaOH}$ for 30 min and transferred to a nylon membrane with positive charge by vacuum blotting. Hybridization of NoV RT-PCR products was performed as described previously (Vinje et al., 1997). Briefly, the nylon membranes were prehybridised for $30 \mathrm{~min}$ at $42{ }^{\circ} \mathrm{C}$ in $20 \mathrm{ml} 2 \times$ SSPE $(300 \mathrm{mM} \mathrm{NaCl}, 20 \mathrm{mM}$ $\mathrm{NaH}_{2} \mathrm{PO}_{4} \mathrm{H}_{2} \mathrm{O}, 2$ mM EDTA, pH 7.4) with $0.1 \%$ SDS. Twenty pmol of each of the 5 '-biotinylated probes (Table 3 ) were added and the membranes were left for $45 \mathrm{~min}$ at $42^{\circ} \mathrm{C}$ to allow hybridization. The membranes were washed three times for $10 \mathrm{~min}$ at $42{ }^{\circ} \mathrm{C}$ with $2 \times$ SSPE and $0.1 \%$ SDS. Subsequently, the membrane was incubated with 1:4000 diluted streptavidin-peroxidase conjugate for 45 min at $42{ }^{\circ} \mathrm{C}$ in $10 \mathrm{ml}$ of $2 \times$ SSPE and $0.5 \%$ SDS. After washing three times (10 min each) with decreasing concentration of SDS $(0.5 \%, 0.1 \%$, and $0 \%)$ in $2 \times$ SSPE, the membranes were incubated for $1 \mathrm{~min}$ with the enhanced chemoluminescence $(E C L)$ detection reagent, and then exposed to an ECL hyperfilm for $15 \mathrm{~min}$.

\subsection{Sequencing}

Exact typing of the RT-PCR positive and Southern blot hybridization confirmed samples was carried out by sequencing. Sequencing of the RT-PCR products was carried out with the ABI Prism BigDye Terminator Cycle Sequencing Ready Reaction kit (Applied Biosystems, Foster City, USA) on an automated sequencer (Applied Biosystems model 3700) using the PCR primer (Table 3). DNA sequences were edited using SeqMan (DNAStar Inc., Konstanz, Germany). Genetic 
classification of the strains was performed using the program Bionumerics (Applied Maths BVBA, Sint-Martens-Latem, Belgium).

\subsection{NoV ELISAS}

The Dako kit for detection of NoV in stool specimen (IDEIA ${ }^{\mathrm{TM}}$ Norwalk-like virus (NLV), Dakocytomation Ltd., Ely, United Kingdom; K6043 two-plate version) utilizes microwells coated with genogroup I or genogroup II specific monoclonal antibodies. The assay was carried out according to the manufacturer's instructions. Briefly, $100 \mu \mathrm{l} 10 \%$ fecal suspension or control sample (provided by the kit) was added to the microwell and incubated simultaneously with $100 \mu \mathrm{l}$ specific genogroup I or genogroup II polyclonal antibody conjugated to horseradish peroxidase. After 120 min incubation the microwells were washed five times with working strength washing buffer. The presence of specifically bound enzyme labeled antibody was determined by addition of $100 \mu$ laqueous solution of 3,3'-, 5,5'-tetramethylbenzidine and hydrogen peroxidase. After 30 min incubation at room temperature the $A_{450 \mathrm{~nm}}$ was measured using $A_{620 \mathrm{~nm}}$ as reference. Any clinical specimen with an $A_{450 \mathrm{~nm}}$ greater than the calculated cut-off value is positive. The cut-off value was calculated by adding 0.10 absorbance units to the negative control value, according to manufacturers instructions.

The Ridascreen kit for detection of NoV in stool specimen (Norwalk-like virus enzyme immunoassay, R-Biopharm AG, Darmstadt, Germany; article number C1401 with production date March 2004) utilizes microwell strips coated with specific antibodies against antigens of several different genotypes. This assay was also carried out according to manufacturer's instructions. Briefly, samples and controls were pipetted into the wells and then incubated at room temperature for $1 \mathrm{~h}$. After washing the wells five times with $300 \mu$ l working strength washing buffer, specific antibodies against NoV conjugated to horseradish peroxidase were added. After $30 \mathrm{~min}$ incubation the microwells were washed five times with $300 \mu \mathrm{l}$ working strength washing buffer. Substrate/chromogen was added to the microwells and incubated $15 \mathrm{~min}$ at room temperature. After $15 \mathrm{~min}$ the reaction was stopped by adding Stop solution and the $A_{450 \mathrm{~nm}}$ was measured using $A_{620 \mathrm{~nm}}$ as reference. The cut-off value was calculated by adding 0.15 absorbance to the mean value of the negative control (according to manufacturer's instructions). Samples which have an absorbance value within $10 \%$ above or below the threshold were re-tested.

\section{Results}

\subsection{Agreement between ELISAs and RT-PCR}

A total of 158 samples from 23 different outbreaks (panel 1) were collected and analyzed using antigen ELISA kits and RT-PCR. A median of 6, ranging from 2 to 16 , samples were tested per outbreak (Table 1 ). Ten (6\%) stool specimen were positive in RT-PCR and both ELISA kits, $71(45 \%)$ were negative by all tests and $77(49 \%)$ samples gave discrepant results. No samples were positive by both ELISA kits and negative by RT-PCR. Three samples from 3 outbreaks were only positive by the Dako kit, 10 samples from 7 outbreaks were only positive by the Ridascreen kit and 29 samples from 10 outbreaks were positive only by RT-PCR. This gave an overall agreement of $51 \%$ between all three tests.

\subsection{Sensitivity and specificity}

In panel $1,74 / 158(47 \%)$ samples were positive by RT-PCR, confirmed by Southern blot hybridization and sequencing. When RT-PCR is regarded as the 
"gold standard", the Dako kit detected 28/74 (38\%) positive samples and the Ridascreen kit detected $27 / 74$ (36\%) positive samples. A total of $84 / 158$ (53\%) samples were tested negative by RT-PCR and confirmed by Southern blotting. From these 84 samples, the Dako kit detected $3(4 \%)$ NoV positive samples and the Ridascreen kit detected $10(12 \%)$ NoV positive samples, resulting in specificities of $96 \%$ and $88 \%$ for the Dako kit and the Ridascreen kit, respectively.

\subsection{Scope of tests}

The second panel of 19 RT-PCR NoV positive samples from 6 different genogroup I strains, 12 genogroup II strains and a genogroup IV, were all tested by both ELISA kits. Four of $6(67 \%)$ strains of genogroup I, 11 of $12(92 \%)$ representative strains of NoV genogroup II and the genogroup IV strain were detected with the Dako kit. The genogroup I test from Dako kit cross-reacted with 6 out of 12 (50\%) genogroup II strains (subtypes; GGII 1, 2, 3 and 4). The genogroup II test did not cross-react with genogroup I stool specimens. The genogroup IV sample did react with the genogroup I test, but not with the genogroup II test (Table 2).

The Ridascreen kit does not discriminate between the genogroups. Only 1 out of 6 (17\%) RT-PCR positive NoV genogroup I samples and 7 of 12 (58\%) RT-PCR positive NoV genogroup II samples were positive by the Ridascreen kit. The genogroup IV sample was negative.

\subsection{Diagnosis of outbreaks}

Most NoV diagnostic tests are done as part of outbreak investigation. Different criteria were used to identify the causative agent of the outbreak, criterion A (two or more positive samples per outbreak to determine the causative agent of an outbreak (Richards et al., 2003)) and B (50\% or more positive samples to determine the causative agent of an outbreak (Vinje and Koopmans, 1996)).

When criterion A was applied, there were 15 NoV positive outbreaks, based on RT-PCR analysis. Of these 15 outbreaks, only $8(53 \%)$ and $9(60 \%)$ were diagnosed as NoV outbreaks by the Dako kit and Ridascreen kit, respectively. These outbreaks consisted of 117 samples, of which $73(62 \%), 30(26 \%)$ and 35 ( $30 \%$ ) were tested NoV positive by RT-PCR, the Dako kit and the Ridascreen kit, respectively. Applying a less stringent criterion (one or more ELISA positive samples per outbreak) resulted in $12 / 15(75 \%)$ or $14 / 15(93 \%)$ NoV positive outbreaks with the Dako kit and Ridascreen kit, respectively (Table 4). The outbreaks which were considered negative for NoV by RT-PCR contain a total 41 samples. Of these samples, $40(98 \%)$ tested negative for NoV by RT-PCR and the Dako kit and $39(95 \%)$ samples were negative for NoV by the Ridascreen kit (Table 5). 
Table 4.

Number of NoV positive samples from outbreaks tested NoV positive by RT-PCR

\begin{tabular}{|l|l|l|l|l|}
\hline $\begin{array}{l}\text { Diagnostic } \\
\text { test }\end{array}$ & \multicolumn{2}{|l|}{$\begin{array}{l}\text { No. of positive samples in NoV outbreaks } \\
(\%)\end{array}$} & \multicolumn{2}{l|}{ No. of positive outbreaks (\%) } \\
\hline & $\begin{array}{l}\text { Criterium } \mathrm{A}^{\mathrm{I}} \\
(n=73)\end{array}$ & $\begin{array}{l}\text { Criterium } \mathrm{B}^{\mathrm{I}} \\
(n=62)\end{array}$ & $\begin{array}{l}\text { Criterium } \mathrm{A}^{\mathrm{I}} \\
(n=15)\end{array}$ & $\begin{array}{l}\text { Criterium } \mathrm{B}^{\mathrm{I}} \\
(n=12)\end{array}$ \\
\hline Dako kit & $30(26)$ & $24(27)$ & $8(53)$ & $5(42)$ \\
\hline Ridascreen kit & $35(30)$ & $29(33)$ & $9(60)$ & $4(33)$ \\
\hline
\end{tabular}

$A^{\mathrm{I}}$ : two or more NoV positive samples per outbreak to identify the causative agent; $B^{\mathrm{I}}: 50 \%$ or more NoV positive samples per outbreak to identify the causative agent.

Table 5.

Proportion of NoV negative samples from outbreaks tested NoV negative by RTPCR

\begin{tabular}{|l|l|l|l|l|}
\hline $\begin{array}{l}\text { Diagnostic } \\
\text { test }\end{array}$ & \multicolumn{2}{|l|}{$\begin{array}{l}\text { No. of negative samples in NoV negative } \\
\text { outbreaks (\%) }\end{array}$} & \multicolumn{2}{l|}{ No. of negative outbreaks (\%) } \\
\hline & Criterium $\mathrm{I}^{\mathrm{I}}(n=41)$ & Criterium $\mathrm{B}^{\mathrm{I}}(n=70)$ & $\begin{array}{l}\text { Criterium } \mathrm{A}^{\mathrm{I}} \\
(n=8)\end{array}$ & $\begin{array}{l}\text { Criterium } \mathrm{B}^{\mathrm{I}} \\
(n=11)\end{array}$ \\
\hline Dako kit & $40(98)$ & $63(90)$ & $8(100)$ & $11(100)$ \\
\hline Ridascreen kit & $39(95)$ & $62(89)$ & $8(100)$ & $11(100)$ \\
\hline
\end{tabular}

$A^{\mathrm{I}}$ : two or more NoV positive samples per outbreak to identify the causative agent; $B^{\mathrm{I}}: 50 \%$ or more NoV positive samples per outbreak to identify the causative agent.

A total of 12 outbreaks positive for NoV were detected by RT-PCR when criterion $B$ was applied. When this criterion for the ELISA kits was applied a total of five $(42 \%)$ and four (33\%) NoV positive outbreaks were detected for the Dako kit and the Ridascreen kit, respectively. These 12 NoV positive outbreaks contained 88 samples, of which 62 (70\%), $24(27 \%)$ and 29 (33\%) were scored as NoV positive by RT-PCR, the Dako kit and the Ridascreen kit, respectively (Table 4). The negative outbreaks contain 70 samples, of which $58(83 \%), 63(90 \%)$ and 62 $(89 \%)$ were tested NoV negative by RT-PCR, the Dako kit and the Ridascreen kit, respectively (Table 5 ). None of the RT-PCR NoV negative outbreaks were found NoV positive with any of the ELISA tests in both criterions.

\section{Discussion}

The high diversity, genetic and antigenic, of NoV poses problems for diagnosis.

At present, RT-PCR is the method used most widely for detection of NoVs in human fecal specimens, however, due to the high genetic diversity constant updating of primers (and probes) is required which adds to the complexity of RTPCR as a diagnostic method. The detection of NoV in human stool specimens by ELISA is based on detection of NoV antigens and may thus be hampered by the 
antigenic diversity of NoV. Several reports that compared antigen detection to RT-PCR showed that ELISAs were easier to carry out but also less sensitive than the RT-PCR methods (Burton-MacLeod et al., 2004, Richards et al., 2003 and Rabenau et al., 2003). The two ELISA kits tested in this study were clearly less sensitive than the RT-PCR in detecting NoV in fecal samples. In outbreaks tested positive for NoV by RT-PCR, the proportion of samples tested positive for NoV by the ELISA kits was less than half the proportion tested positive for NoV by RT$\mathrm{PCR}$, irrespective of the criteria chosen to define a NoV outbreak.

A sensitivity of $38 \%$ was found for the Dako kit, similar to a previous observation (reported sensitivities of $39 \%$ and $31 \%$ for the Dako kit in samples from NoV outbreaks found positive by RT-PCR; Burton-MacLeod et al., 2004 and Rabenau et al., 2003, respectively). A sensitivity and specificity of $36 \%$ and $88 \%$ were found for the Ridascreen kit, which is comparable to the Dako kit. Dimitriadis and Marshall (2005) reported a sensitivity and specificity of $71 \%$ and $47 \%$ for single specimen diagnosis, respectively, and an even higher sensitivity and specificity for outbreak diagnosis for the Ridascreen kit. However, based on this study, it is assumed that at least $40 \%$ of the NoV outbreaks would not be diagnosed as NoV outbreaks using any of the two commercial ELISAs evaluated.

The most dominant type of NoV, at least in epidemic years in Europe and Australia, is GGII.4 (Kirkwood et al., 2005 and Lopman et al., 2004). A high sensitivity for GGII.4 viruses could in daily practice lead to a relatively good detection of NoV outbreaks. However, in this study the sensitivity of both ELISA kits tested for NoV GGII.4 was not different from the overall sensitivity.

The overall specificity of the Dako kit was satisfactory, none of the confirmed Astrovirus or Rotavirus containing samples cross-reacted with the Dako kit. The specificity of the Ridascreen kit was less than that of the Dako kit and the Ridascreen kit showed unexplained cross-reactivity with one of the samples containing rotaviruses. When seeking broad detection, a feature that is important given the high level of genetic and antigenic diversity of NoVs, the Ridascreen assay was clearly less optimal since viruses belonging to six genotypes were not detected in this study. Remarkably, viruses of GGI.3 and GGI.5 were not detected by any of the ELISAs.

The Dako kit consists of separate tests for genogroup I and II, but discrimination between genogroups was poor, 6 out of 12 genogroup II samples reacted with the EIA genogroup I wells. The poor discrimination was observed previously, however, in that study, $7 \%$ of the genogroup I samples reacted with the EIA genogroup II wells (Burton-MacLeod et al., 2004). Also, the relevance of the ability to discriminate between genogroup I and II is unclear; there is no difference between the clinical pictures of NoV genogroup I or II, and typing to genogroup level is not sufficiently precise for molecular epidemiology studies (Koopmans et al., 2001).

In conclusion, because of its rapidity and simplicity the ELISA kits may be useful for screening of large numbers of clinical samples during outbreaks. The assays are not suitable for diagnosis of infection in individual patients, or for genotype assignment. Because of the low sensitivity, RT-PCR remains the "gold standard" for routine diagnosis of NoV in samples from patients with gastroenteritis. 


\title{
Acknowledgements
}

\author{
This work was supported by the European Commission, DG Research Quality of \\ Life Program, Fifth Framework (QLK1-CT-1999-00594), Sixth Framework (SP22- \\ CT-2004-502571) and DG SANCO (2003213).
}

\section{References}

Atmar and Estes, 2001 R.L. Atmar and M.K. Estes, Diagnosis of noncultivatable gastroenteritis viruses, the human caliciviruses, Clin. Microbiol. Rev. 14 (2001) (1), pp. 15-37.

Boom et al., 1990 R. Boom, C.J. Sol, M.M. Salimans, C.L. Jansen, P.M. Wertheim-van Dillen and J. van der Noordaa, Rapid and simple method for purification of nucleic acids, J. Clin. Microbiol. 28 (1990) (3), pp. 495-503.

Burton-MacLeod et al., 2004 J.A. Burton-MacLeod, E.M. Kane, R.S. Beard, L.A. Hadley, R.I. Glass and T. Ando, Evaluation and comparison of two commercial enzyme-linked immunosorbent assay kits for detection of antigenically diverse human noroviruses in stool samples, J. Clin. Microbiol. 42 (2004) (6), pp. 2587-2595.

de Wit et al., 2001 M.A. de Wit, M.P. Koopmans, L.M. Kortbeek, W.J. Wannet, J. Vinje, F. van Leusden, A.I. Bartelds and Y.T. van Duynhoven, Sensor, a population-based cohort study on gastroenteritis in The Netherlands: incidence and etiology, Am. J. Epidemiol. 154 (2001) (7), pp. 666674.

Dimitriadis and Marshall, 2005 A. Dimitriadis and J.A. Marshall, Evaluation of a commercial enzyme immunoassay for detection of norovirus in outbreak specimens, Eur. J. Clin. Microbiol. Infect. Dis. 24 (2005) (9), pp. 615-618.

Duizer et al., 2004 E. Duizer, K.J. Schwab, F.H. Neill, R.L. Atmar, M.P. Koopmans and M.K. Estes, Laboratory efforts to cultivate noroviruses, J. Gen. Virol. 85 (2004) (1), pp. 79-87.

Green et al., 2001 K.Y. Green, R.M. Chanock and A.Z. Kapikian, Human caliciviruses, Fields Virology, Lippincott Williams \& Wilkins, Philadelphia (2001) pp. 841-874.

Kirkwood et al., 2005 C.D. Kirkwood, R. Clark, N. Bogdanovic-Sakran and A. Bishop, A 5-year study of the prevalence and genetic diversity of human caliciviruses associated with sporadic cases of acute gastroenteritis in young children admitted to hospital in Melbourne, Australia (1998-2002), J. Med. Virol. 77 (2005) (1), pp. 96-101.

Koopmans et al., 2001 M. Koopmans, J. Vinje, E. Duizer, M. de Wit and Y. van Duijnhoven, Molecular epidemiology of human enteric caliciviruses in The Netherlands, Novartis Found. Symp. 238 (2001), pp. 197-214 discussion 214-218.

Koopmans et al., 2003 M. Koopmans, E. van Strien and H. Vennema, Molecular epidemiology of human caliciviruses. In: U. Desselberger and J. Gray, Editors, Viral Gastroenteritis. Perspectives in Medical Virology, Elsevier Science, Amsterdam (2003), pp. 523-554.

Lopman et al., 2004 B. Lopman, H. Vennema, E. Kohli, P. Pothier, A. Sanchez, A. Negredo, J. Buesa, E. Schreier, M. Reacher, D. Brown, J. Gray, M. Iturriza, C. Gallimore, B. Bottiger, K.O. Hedlund, M. Torven, C.H. von Bonsdorff, L. Maunula, M. Poljsak-Prijatelj, J. Zimsek, G. Reuter, G. Szucs, B. Melegh, L. Svennson, Y. van Duijnhoven and M. Koopmans, Increase in viral gastroenteritis outbreaks in Europe and epidemic spread of new norovirus variant, Lancet 363 (2004) (9410), pp. 682-688.

Mohamed et al., 2006 N. Mohamed, S. Belak, K.O. Hedlund and J. Blomberg, Experience from the development of a diagnostic single tube real-time PCR for human caliciviruses, Norovirus genogroups I and II, J. Virol. Meth. 132 (2006) (1-2), pp. 69-76. 
Rabenau et al., 2003 H.F. Rabenau, M. Stürmer, S. Buxbaum, A. Walczok, W. Preiser and H.W. Doerr, Laboratory diagnosis of Norovirus: which method is the best?, Intervirology 46 (2003), pp. 232-238.

Richards et al., 2003 A.F. Richards, B. Lopman, A. Gunn, A. Curry, D. Ellis, H. Cotterill, S. Ratcliffe, M. Jenkins, H. Appleton, C.I. Gallimore, J.J. Gray and D.W. Brown, Evaluation of a commercial ELISA for detecting Norwalk-like virus antigen in faeces, J. Clin. Virol. 26 (2003) (1), pp. 109-115.

Richards et al., 2004 G.P. Richards, M.A. Watson, R.L. Fankhauser and S.S. Monroe, Genogroup I and II noroviruses detected in stool samples by real-time reverse transcription-PCR using highly degenerate universal primers, Appl. Environ. Microbiol. 70 (2004) (12), pp. 7179-7184.

Rockx et al., 2005 B.H. Rockx, W.M. Bogers, J.L. Heeney, G. van Amerongen and M.P. Koopmans, Experimental norovirus infections in non-human primates, J. Med. Virol. 75 (2005) (2), pp. 313-320.

Vennema et al., $2002 \mathrm{H}$. Vennema, E. de Bruin and M. Koopmans, Rational optimization of generic primers used for Norwalk-like virus detection by reverse transcriptase polymerase chain reaction, $J$. Clin. Virol. 25 (2002) (2), pp. 233-235.

Vinje and Koopmans, 1996 J. Vinje and M.P. Koopmans, Molecular detection and epidemiology of small round-structured viruses in outbreaks of gastroenteritis in The Netherlands, J. Infect. Dis. 174 (1996) (3), pp. 610-615

Vinje et al., 1997 J. Vinje, S.A. Altena and M.P. Koopmans, The incidence and genetic variability of small round-structured viruses in outbreaks of gastroenteritis in The Netherlands, J. Infect. Dis. 176 (1997) (5), pp. 1374-1378.

Vipond et al., 2000 I.B. Vipond, E. Pelosi, J. Williams, C.R. Ashley, P.R. Lambden, I.N. Clarke and E.O. Caul, A diagnostic EIA for detection of the prevalent SRSV strain in United Kingdom outbreaks of gastroenteritis, J. Med. Virol. 61(2000) (1), pp. 132-137. 